\title{
Inventory Model for Decaying Items with Multivariate Demand and Variable Holding Cost under the Facility of Trade-Credit
}

\author{
Anupam Swami \\ Assistant Professor \\ Govt. P.G. College \\ Sambhal, U.P.
}

\author{
Sarla Pareek \\ Professor and HOD \\ Banasthali University \\ Jaipur, RAJ.
}

\author{
S.R. Singh, Ph.D. \\ Associate Professor \\ CCS University \\ Meerut, U.P.
}

\author{
Ajay Singh \\ Yadav, Ph.D. \\ Assistant Professor \\ SRM University \\ NCR Campus, GZB
}

\begin{abstract}
In this study, an inventory model for deteriorating items with multivariate demand and variable holding cost is developed. The facility of allowable delay in payment is also taken into consideration. During this period retailer can use the ensued money from sales of the supplied goods to earn interest. Demand rate is a function of on hand inventory and selling price of the item and it is considered that the stock affects the demand rate up to an assured time. Therefore, retailer will order more quantity to stimulate demand rate and to earn more money. Different cases of allowable delay in payment are discussed. The objective of this study is to maximize the retailer's total profit per unit time. The results are illustrated with some numerical examples and sensitivity analysis for each case is also carried out.
\end{abstract}

\section{Keywords}

Inventory Model, Sensitivity Analysis, and consumption rate

\section{INTRODUCTION}

The classical inventory models consider the demand rate to be either constant or time-dependent but independent of the available stock status. However, in many practical situations customers' purchasing manners may be affected by factors such as selling price, on hand inventory and so on. As deliberated by Levin et al. (1972) and Silver and Peterson (1985), sales at the retail point tend to be proportional to inventory displayed and a large piles of goods exhibited in a supermarket will escort the purchasers to buy more. Many marketing researchers and practitioners have paying attention to investigate the modelling aspects of this occurrence. Gupta and Vrat (1986) first designed a model for consumption environment to minimize the cost with the assumption that demand rate is a function of the initial stock level. Mandal and Phaujdar (1989), Datta and Pal (1990), Padmanabhan and Vrat (1995) further developed inventory models under stockdependent consumption rate with some different assumptions. Since a firm may use a pricing strategy to stimulate demand for its seasonal goods, the inventory problems with selling price and stock dependent demand cannot be disregarded. Urban and Baker (1997) investigated a deterministic inventory problem in with multivariate demand rate. Datta and Paul (2001) analyzed an inventory system where the consumption rate of the goods is affected by both displayed stock level and selling price. You (2005) investigated an inventory model by considering price and time dependent demand rate. Some inspiring research articles associated to this research environment are, You and Hsieh (2007), Chang et al. (2010), Lee and Dye (2012).
In today's business communications, it is more and more frequent to see that the supplier allows the retailer a fixed time (trade-credit) period. This provides an advantage to the retailer, as he/she does not has to pay the supplier immediately after receiving the items; in contrast during the delay period an interest can be earned by the retailer on the accumulated revenue. On the other hand, the strategy of allowing a permissible delay period is also beneficial for the supplier as it attracts new retailers/purchasers who consider this policy to be a type of purchasing cost reduction. Based on this phenomenon, Goyal (1985) analyzed the effect of trade credit on the optimal inventory policy. Later on, Aggarwal and Jaggi (1995) extended Goyal (1985) model with an exponential deterioration rate under the policy of allowable delay in payments. Jamal et al. (1997), Chang and Dye (2001) put forwarded inventory models with trade-credit policy by considering shortages. Teng (2002) proposed an inventory model by estimating the difference between unit selling price and unit cost and recognized an easy analytical closed-form solution to the problem. Sana and Chaudhuri (2008) analyzed optimal trade-credit policies when a price discount is offered. Khanra et al. (2011) proposed an EOQ (Economic Order Quantity) model for a deteriorating item having time dependent demand rate when delay in payment is permitted. Teng et al. (2012) deliberated an inventory model with nondecreasing demand and trade-credit financing.

The above mentioned literature reveals that inventory models for decaying items under the condition of allowable delay in payment with variable holding cost, stock and price dependent demand rate, while the on hand inventory affects the demand rate up to a assured period are not discussed so far. Therefore, in this study, an inventory model for deteriorating items with multivariate rate is developed. It is assumed that a trade credit period is offered by the supplier to the retailer. The time dependent holding cost is also taken into consideration. Three cases are discussed according to the situation of the delay period. To validate the concept of this study numerical examples are provided and sensitivity analysis for different cases is also discussed. The concavity of the profit function in each case is disclosed graphically.

\section{NOTATIONS AND ASSUMPTIONS}

The following notation is used throughout the paper:
$I(t)$
The inventory level at any time $t, t \geq 0$
$T \quad$ Cycle length (time units)
$Q \quad$ The replenishment/order size (units/cycle) 
$\theta \quad$ Deterioration rate of on hand inventory during cycle time

$T_{1} \quad$ Time up to which demand is affected by on hand stock

$I_{e} \quad$ Interest earned (/\$/cycle)

$I_{c} \quad$ Interest charges per $\$$ investment in inventory per cycle

M The trade credit period length per cycle

$p \quad$ Unit selling price per item (\$)

$h+\delta t \quad$ Holding cost per unit per unit time (\$)

$C_{p} \quad$ Purchasing cost per unit (\$)

$C_{d} \quad$ Purchasing cost per unit (\$)

A Ordering cost for placing an order (\$/order)

\section{ASSUMPTIONS}

In developing the mathematical model, the following assumptions are made:
1. The demand rate, $D(t)$ is a function of stock and price and is define $D(t)=a+b I(t)-c p$, where a is positive constant, $b$ is the stockdependent consumption rate parameter, $0 \leq b \leq 1$, $c>0$ is the selling price dependent factor and $\mathrm{I}(\mathrm{t})$ is the inventory level at time $t$.

2. The inventory system involves only one type of perishable item and the planning horizon is infinite.

3. The replenishment rate is infinite.

4. Holding cost per unit per unit time is $h+\delta t$ where $h>0,0<\delta<1$.

5. The deteriorating rate, $\theta(0<\theta<1)$, is constant and there is no replacement or repair of deteriorated units during the period under consideration.

\section{MODEL FORMULATIONS}

Here, the replenishment policy of a deteriorating item with variable demand rate is considered. The objective of the inventory system is to determine the optimal ordering quantity and the length of ordering cycle. The behavior of the inventory system at any time $t$ is depicted in Figure 1 . There may arise three cases according to the position of the delay period $\mathrm{M}$ as shown in Figure 1.

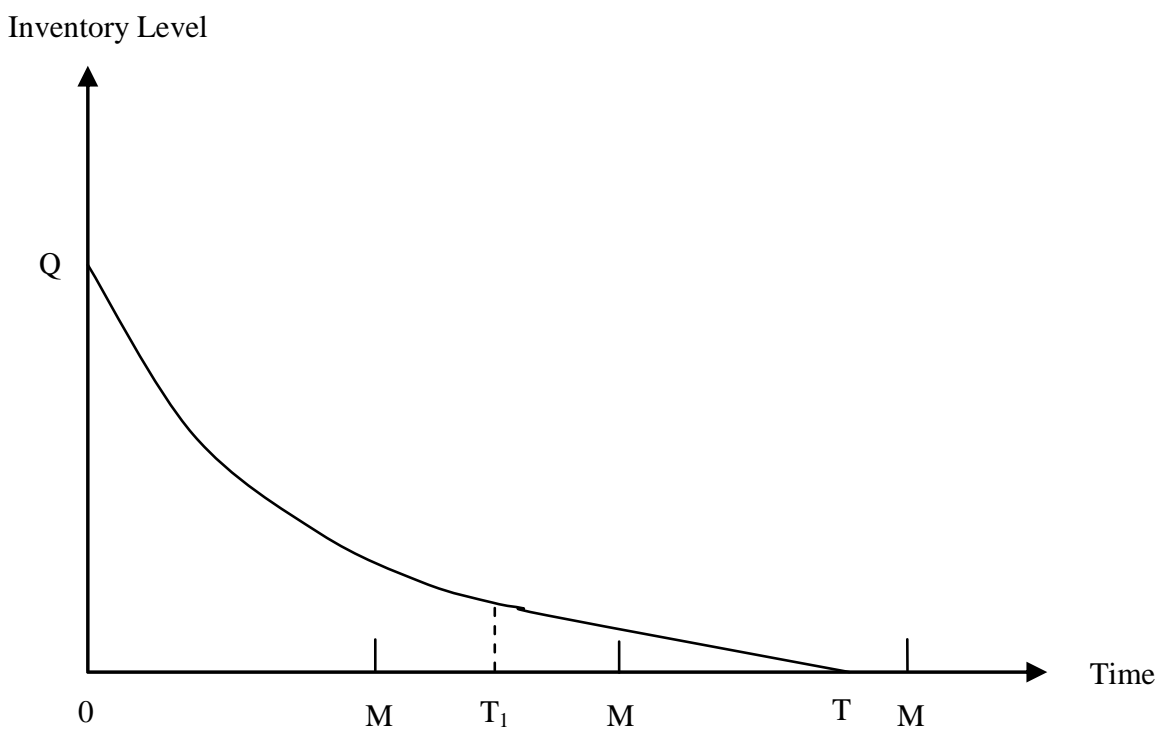

Figure 1: The graphical representation of inventory system

Replenishment is made at time $t=0$ and the order size is $\mathrm{Q}$. During the period $\left[0, T_{1}\right]$ the available stock and selling price of the item both affect the demand rate after that during the period $\left[T_{1}, T\right]$ only selling price influences the demand rate. The inventory level during the period $[0, T]$ decreases

$$
\begin{array}{ll}
I_{1}^{\prime}(t)+\theta I(t)=-(a+b I(t)-c p) & 0 \leq \mathrm{t} \leq \mathrm{T}_{1} \\
I_{2}^{\prime}(t)+\theta I(t)=-(a-c p) & \mathrm{T}_{1} \leq \mathrm{t} \leq \mathrm{T}
\end{array}
$$

due to the combined effect of the demand rate and deterioration of the item and ultimately falls to zero at $t=T$. Hence, the differential equations representing the inventory status during the period $[0, T]$ are given by

With boundary conditions $I_{1}(0)=Q, I_{2}(T)=0$. Solving eq. ( 1 ) and (2) we get 


$$
\begin{aligned}
& I_{1}(t)=\left[\left(Q+\frac{(a-c p)}{(b+\theta)}\right) e^{-(b+\theta) t}-\frac{(a-c p)}{(b+\theta)}\right] \\
& I_{2}(t)=\frac{(a-c p)}{\theta}\left(e^{\theta(T-t)}-1\right)
\end{aligned}
$$

Since inventory level is continuous at $t=T_{1}$, so we have $I_{1}\left(T_{1}\right)=I_{2}\left(T_{1}\right)$

$\Rightarrow Q=\left[\frac{(a-c p)}{\theta}\left(e^{\theta\left(T-T_{1}\right)}-1\right)-\frac{(a-c p)}{(b+\theta)}\left(e^{-(b+\theta) T_{1}}-1\right)\right] e^{(b+\theta) T_{1}}$

Now, ordering cost per unit time is $\mathrm{OC}$ and is given by

$O C=\frac{A}{T}$

Purchasing cost per unit time is $\mathrm{PC}$ and is given by

$$
P C=\frac{C_{p} Q}{T}
$$

Inventory carrying cost per unit time is $\mathrm{HC}$ and is given by

$$
\begin{aligned}
H C=\frac{1}{T} & {\left[\int_{0}^{T_{1}}(h+\delta t) I_{1}(t) d t+\int_{T_{1}}^{T_{2}}(h+\delta t) I_{2}(t) d t\right] } \\
\Rightarrow H C=\frac{1}{T} & {\left[\left(Q+\frac{(a-c p)}{(b+\theta)}\right)\left\{\frac{h}{(b+\theta)}+\frac{\delta}{(b+\theta)^{2}}-\left(\frac{\left(h+\delta T_{1}\right)}{(b+\theta)}+\frac{\delta}{(b+\theta)^{2}}\right) e^{-(b+\theta) T_{1}}\right\}+\frac{b(a-c p)}{\theta(b+\theta)}\left(h T_{1}+\frac{\delta T_{1}^{2}}{2}\right)\right.} \\
& \left.+\frac{(a-c p)}{\theta}\left\{\left(\frac{\left(h+\delta T_{1}\right)}{\theta}+\frac{\delta}{\theta^{2}}\right) e^{\theta\left(T-T_{1}\right)}-\left(\frac{(h+\delta T)}{\theta}+\frac{\delta}{\theta^{2}}\right)\right\}-\frac{(a-c p)}{\theta}\left(h T+\frac{\delta T^{2}}{2}\right)\right]
\end{aligned}
$$

Deterioration cost per unit time is DC and is given by

$$
\begin{aligned}
& D C=\frac{C_{d}}{T}\left[\int_{0}^{T_{1}} \theta I_{1}(t) d t+\int_{T_{1}}^{T_{2}} \theta I_{2}(t) d t\right] \\
& \Rightarrow D C=\frac{C_{d}}{T}\left[\frac{\left(1-e^{-(b+\theta) T_{1}}\right)}{(b+\theta)}\left(Q+\frac{(a-c p)}{(b+\theta)}\right)-\frac{(a-c p) T_{1}}{(b+\theta)}+\frac{(a-c p)}{\theta}\left\{\frac{1}{\theta}\left(e^{\theta\left(T-T_{1}\right)}-1\right)-\left(T-T_{1}\right)\right\}\right]
\end{aligned}
$$

Sales revenue per unit time is SR and is given by

$$
\begin{aligned}
& S R=p\left[\int_{0}^{T_{1}}\left(a+b I_{1}(t)-c p\right) d t+\int_{T_{1}}^{T}(a-c p) d t\right] \\
& \Rightarrow S R=p\left[(a-c p) T+b\left\{\left(Q+\frac{(a-c p)}{(b+\theta)}\right) \frac{\left(1-e^{-(b+\theta) T_{1}}\right)}{(b+\theta)}-\frac{(a-c p) T_{1}}{(b+\theta)}\right\}\right]
\end{aligned}
$$

Now, according to the position of delay period $\mathrm{M}$ there arise three cases:

Case (1) $\mathrm{M} \leq \mathrm{T}_{1}<\mathrm{T}$

$\leq \mathrm{M}<\mathrm{T}$

Case (2) $\mathrm{T}_{1}$

Case (3) $M \geq T$

We shall discuss these three cases one by one.

Case (1): $M \leq T_{1}<T$
During the credit period the buyer can use the sale revenue to earn an interest and can collect more capital. So, interest earned per unit time is $\mathrm{IE}_{1}$ and is given by

$$
I E_{1}=\frac{p I_{e}}{T}\left[\int_{0}^{M}\left(a+b I_{1}(t)-c p\right) t d t\right]
$$


$\Rightarrow I E_{1}=\frac{p I_{e}}{T}\left[\frac{\theta(a-c p) M^{2}}{2(b+\theta)}+b\left(Q+\frac{(a-c p)}{(b+\theta)}\right)\left\{\frac{1}{(b+\theta)^{2}}-\left(\frac{M}{(b+\theta)}+\frac{1}{(b+\theta)^{2}}\right) e^{-(b+\theta) M}\right\}\right]$

After, the credit period the buyer/retailer has to pay the interest for the goods still in stock with annual rate $I_{c}$.

Therefore, interest charged per unit time is $\mathrm{IC}_{1}$ and is given by

$$
\begin{aligned}
& I C_{1}=\frac{C_{p} I_{c}}{T}\left[\int_{M}^{T_{1}} I_{1}(t) d t+\int_{T_{1}}^{T} I_{2}(t) d t\right] \\
& \Rightarrow I C_{1}=\frac{C_{p} I_{c}}{T}\left[\left(Q+\frac{(a-c p)}{(b+\theta)}\right) \frac{\left(e^{-(b+\theta) M}-e^{-(b+\theta) T_{1}}\right)}{(b+\theta)}-\frac{(a-c p)}{(b+\theta)}\left(T_{1}-M\right)+\frac{(a-c p)}{\theta}\left\{\frac{\left(e^{\theta\left(T-T_{1}\right)}-1\right)}{\theta}-\left(T-T_{1}\right)\right\}\right] .
\end{aligned}
$$

The total profit per unit time for this case is $\mathrm{AP}_{1}$ and is given by

$$
A P_{1}(T, p)=\left[\left(S R+I E_{1}\right)-\left(O C+P C+H C+D C+I C_{1}\right)\right]
$$

The objective of this study is to maximize the total profit per unit time $\mathrm{AP}_{1}(\mathrm{~T}, \mathrm{p})$. The necessary conditions for maximizing the profit are

$$
\frac{\partial A P_{1}(T, p)}{\partial T}=0
$$

$\frac{\partial A P_{1}(T, p)}{\partial p}=0$

$\frac{\partial^{2} A P_{1}(T, p)}{\partial T^{2}}<0, \frac{\partial^{2} A P_{1}(T, p)}{\partial p^{2}}<0$ and $\frac{\partial^{2} A P_{1}(T, p)}{\partial T^{2}} \frac{\partial^{2} A P_{1}(T, p)}{\partial p^{2}}-\left(\frac{\partial^{2} A P_{1}(T, p)}{\partial T \partial p}\right)^{2}>0$

Case (2): $T_{1} \leq M \leq T$

In this case, interest earned per unit time is $\mathrm{IE}_{2}$ and is given by

$$
\begin{gathered}
I E_{2}=\frac{p I_{e}}{T}\left[\int_{0}^{T_{1}}\left(a+b I_{1}(t)-c p\right) t d t+\left(M-T_{1}\right) \int_{0}^{T_{1}}\left(a+b I_{1}(t)-c p\right) d t+\int_{T_{1}}^{M}(a-c p) t d t\right] \\
\Rightarrow I E_{2}=\frac{p I_{e}}{T}\left[\frac{\theta(a-c p) T_{1}^{2}}{2(b+\theta)}-b\left(Q+\frac{(a-c p)}{(b+\theta)}\right)\left\{\frac{T_{1} e^{-(b+\theta) T_{1}}}{(b+\theta)}+\frac{\left(e^{-(b+\theta) T_{1}}-1\right)}{(b+\theta)^{2}}\right\}+\frac{(a-c p)\left(M^{2}-T_{1}^{2}\right)}{2}\right. \\
\left.+\left(M-T_{1}\right)\left\{\frac{\theta(a-c p) T_{1}}{(b+\theta)}-\frac{b}{(b+\theta)}\left(Q+\frac{(a-c p)}{(b+\theta)}\right)\left(e^{-(b+\theta) T_{1}}-1\right)\right\}\right]
\end{gathered}
$$

For this case, interest charged per unit time is $\mathrm{IC}_{2}$ and is given by

$$
I C_{2}=\frac{C_{p} I_{c}}{T}\left[\int_{M}^{T} I_{2}(t) d t\right]=\frac{(a-c p) C_{p} I_{c}}{\theta T}\left[\frac{\left(e^{\theta(T-M)}-1\right)}{\theta}-(T-M)\right]
$$

The total profit per unit time for this case is $\mathrm{AP}_{2}$ and is given by

$$
A P_{2}(T, p)=\left[\left(S R+I E_{2}\right)-\left(O C+P C+H C+D C+I C_{2}\right)\right]
$$

Again, the objective of this study is to determine the optimal values of $\mathrm{T}$ and $\mathrm{p}$, when $\mathrm{T}_{1}<\mathrm{M} \leq \mathrm{T}$, in order to maximize the total profit per unit time $\mathrm{AP}_{2}(\mathrm{~T}, \mathrm{p})$. The necessary conditions $\frac{\partial A P_{2}(T, p)}{\partial T}=0$ for maximizing the profit are 
$\frac{\partial A P_{2}(T, p)}{\partial p}=0$

observed from (5). Also, the optimal value $\mathrm{AP}_{2}\left(\mathrm{~T}^{*}, \mathrm{p}^{*}\right)$ of the average profit can be determined by (19) provided they satisfy the sufficiency conditions that are given as follows

From equation (20) and (21) with the help of software Mathematica-8.0, we can determine the optimum values of $T^{*}$ and $\mathrm{p}^{*}$ simultaneously and optimal order size $\left(\mathrm{Q}^{*}\right)$ can be

$\frac{\partial^{2} A P_{2}(T, p)}{\partial T^{2}}<0, \frac{\partial^{2} A P_{2}(T, p)}{\partial p^{2}}<0$ and $\frac{\partial^{2} A P_{2}(T, p)}{\partial T^{2}} \frac{\partial^{2} A P_{2}(T, p)}{\partial p^{2}}-\left(\frac{\partial^{2} A P_{2}(T, p)}{\partial T \partial p}\right)^{2}>0$

Case (3): $\mathrm{T}<\mathrm{M}$

In this case, interest earned per unit time is $\mathrm{IE}_{3}$ and is given by

$$
\begin{aligned}
& I E_{3}=\frac{p I_{e}}{T}\left[\int_{0}^{T_{1}}\left(a+b I_{1}(t)-c p\right) t d t+\left(M-T_{1}\right) \int_{0}^{T_{1}}\left(a+b I_{1}(t)-c p\right) d t+\int_{T_{1}}^{T}(a-c p) t d t+(M-T) \int_{T_{1}}^{T}(a-c p) d t\right] \\
& I E_{3}=\frac{p I_{e}}{T}\left[\frac{\theta(a-c p) T_{1}^{2}}{2(b+\theta)}-b\left(Q+\frac{(a-c p)}{(b+\theta)}\right)\left\{\frac{T_{1} e^{-(b+\theta) T_{1}}}{(b+\theta)}+\frac{\left(e^{-(b+\theta) T_{1}}-1\right)}{(b+\theta)^{2}}\right\}+\frac{(a-c p)\left(T^{2}-T_{1}^{2}\right)}{2}\right. \\
& \left.\qquad+\left(M-T_{1}\right)\left\{\frac{\theta(a-c p) T_{1}}{(b+\theta)}-\frac{b}{(b+\theta)}\left(Q+\frac{(a-c p)}{(b+\theta)}\right)\left(e^{-(b+\theta) T_{1}}-1\right)\right\}+(M-T)(a-c p)\left(T-T_{1}\right)\right] \\
& \text { Interest charged per unit time is IC } \mathrm{IC}_{3} \text { and is given by } \quad \text { (24) } \\
& I C_{3}=0 \\
& \text { The total profit per unit time for this case is } \mathrm{AP}_{3} \text { and is given } \quad \frac{\partial A P_{3}(T, p)}{\partial T}=0 \\
& \text { by }
\end{aligned}
$$

$$
A P_{3}(T, p)=\left[\left(S R+I E_{3}\right)-\left(O C+P C+H C+D C+I C_{3}\right)\right]
$$

From equation (26) and (27) with the help of software Mathematica-8.0, we can determine the optimum values of $T^{*}$ and $\mathrm{p}^{*}$ simultaneously and optimal order size $\left(\mathrm{Q}^{*}\right)$ can be observed from (5).

$\mathrm{T}$ and $\mathrm{p}$, when $\mathrm{M}>\mathrm{T}$, in order to maximize the total profit per unit time $\mathrm{AP}_{3}(\mathrm{~T}, \mathrm{p})$. The necessary conditions for maximizing the profit are

$\frac{\partial^{2} A P_{3}(T, p)}{\partial T^{2}}<0, \frac{\partial^{2} A P_{3}(T, p)}{\partial p^{2}}<0$ and $\frac{\partial^{2} A P_{3}(T, p)}{\partial T^{2}} \frac{\partial^{2} A P_{3}(T, p)}{\partial p^{2}}-\left(\frac{\partial^{2} A P_{3}(T, p)}{\partial T \partial p}\right)^{2}>0$

\section{NUMERICAL EXAMPLES AND SENSITIVITY ANALYSIS}

Example (1): (For case (1) $\mathrm{M} \leq \mathrm{T}_{1}<\mathrm{T}$ ) To illustrate the model we consider the following data on the basis of previous study:

$\mathrm{a}=200, \mathrm{~b}=0.5, \mathrm{c}=1.8, \theta=0.3, \mathrm{I}_{\mathrm{e}}=0.15, \mathrm{I}_{\mathrm{c}}=0.17, \mathrm{M}=0.25, \mathrm{~h}=6$, $\delta=0.1, \mathrm{C}_{\mathrm{d}}=3, \mathrm{~A}=130, \mathrm{C}_{\mathrm{p}}=40, \mathrm{~T}_{1}=0.32$.

Then, the optimal solution is $\mathrm{T}^{*}=0.479925, \mathrm{p}^{*}=77.7625$, $Q^{*}=34.5945$

and $\mathrm{AP}_{1}\left(\mathrm{~T}^{*}, \mathrm{p}^{*}\right)=1995.04$.

The concavity of the profit function for case (1) is shown graphically in Figure 2.

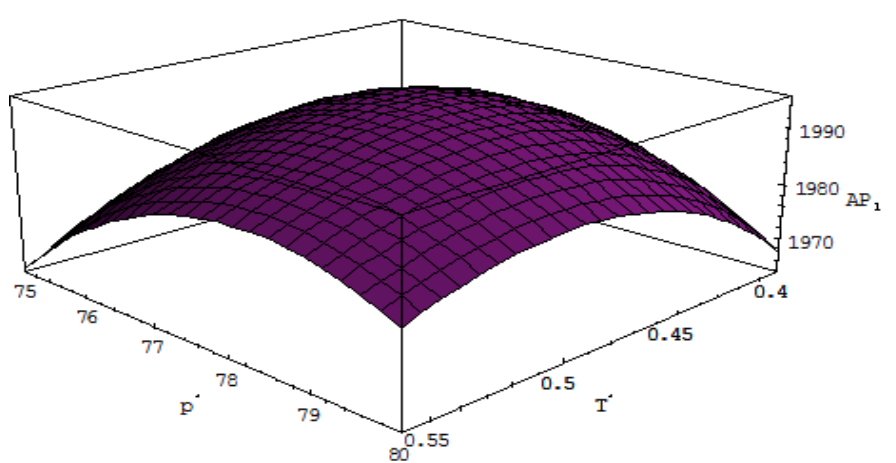

Figure 2. The concavity of the profit function (for case (1)) w.r.t. selling price and cycle length 
Table 1: The sensitivity analysis for case (1) is performed by changing the value of each of the parameters by $\pm 10 \%$ and $\pm 20 \%$, taking one parameter at a time and keeping the remaining parameters unchanged

\begin{tabular}{|c|c|c|c|c|c|}
\hline Parameter & $\%$ Change & $\mathrm{T}^{*}$ & $\mathrm{p}^{*}$ & $\mathrm{Q}^{*}$ & $\mathrm{AP}_{1}\left(\mathrm{~T}^{*}, \mathrm{p}^{*}\right)$ \\
\hline \multirow[t]{4}{*}{ A } & -20 & 0.537022 & 66.9978 & 25.7843 & 740.169 \\
\hline & -10 & 0.500892 & 72.3341 & 30.1190 & 1303.56 \\
\hline & +10 & 0.468168 & 83.2468 & 39.3156 & 2813.14 \\
\hline & +20 & 0.462501 & 88.7680 & 49.3158 & 3706.31 \\
\hline \multirow[t]{4}{*}{ B } & -20 & 0.459121 & 77.6623 & 32.2959 & 1940.28 \\
\hline & -10 & 0.469450 & 77.7127 & 33.4238 & 1967.29 \\
\hline & +10 & 0.490551 & 77.8117 & 35.8098 & 2023.55 \\
\hline & +20 & 0.501336 & 77.8602 & 37.0721 & 2052.82 \\
\hline \multirow[t]{4}{*}{$\mathrm{C}$} & -20 & 0.492831 & 91.7296 & 40.3270 & 3366.50 \\
\hline & -10 & 0.483872 & 83.9593 & 37.2182 & 2593.31 \\
\hline & +10 & 0.480230 & 72.7139 & 32.3118 & 1523.84 \\
\hline & +20 & 0.484433 & 68.5306 & 30.2708 & 1147.95 \\
\hline \multirow[t]{4}{*}{$\Theta$} & -20 & 0.507888 & 77.5893 & 36.4813 & 2037.60 \\
\hline & -10 & 0.493404 & 77.6772 & 35.5070 & 2016.08 \\
\hline & +10 & 0.467339 & 77.8454 & 33.7373 & 1974.44 \\
\hline & +20 & 0.455552 & 77.9260 & 32.9301 & 1954.27 \\
\hline \multirow[t]{4}{*}{$\mathrm{I}_{\mathrm{e}}$} & -20 & 0.485451 & 77.8408 & 34.9621 & 1984.38 \\
\hline & -10 & 0.482697 & 77.8018 & 34.7790 & 1989.70 \\
\hline & +10 & 0.477135 & 77.7230 & 34.4083 & 2000.41 \\
\hline & +20 & 0.474326 & 77.6833 & 34.2204 & 2005.81 \\
\hline \multirow[t]{4}{*}{$\mathrm{I}_{\mathrm{c}}$} & -20 & 0.489664 & 77.7852 & 35.3638 & 1999.83 \\
\hline & -10 & 0.484687 & 77.7738 & 34.9703 & 1997.40 \\
\hline & +10 & 0.475363 & 77.7514 & 34.2350 & 1992.75 \\
\hline & +20 & 0.470989 & 77.7405 & 33.8908 & 1990.54 \\
\hline \multirow[t]{4}{*}{$\mathrm{H}$} & -20 & 0.492194 & 77.6913 & 35.6704 & 2014.62 \\
\hline & -10 & 0.485943 & 77.7271 & 35.1217 & 2004.76 \\
\hline & +10 & 0.474124 & 77.7975 & 34.0871 & 1985.45 \\
\hline & +20 & 0.468528 & 77.8322 & 33.5985 & 1976.00 \\
\hline $\mathrm{C}_{\mathrm{d}}$ & -20 & 0.481707 & 77.7519 & 34.7505 & 1997.94 \\
\hline
\end{tabular}




\begin{tabular}{|l|l|l|l|l|l|}
\hline \multirow{4}{*}{} & -10 & 0.480813 & 77.7572 & 34.6722 & 1996.49 \\
\cline { 2 - 6 } & +10 & 0.479041 & 77.7678 & 34.5173 & 1993.59 \\
\cline { 2 - 6 } & +20 & 0.478162 & 77.7731 & 34.4401 & 1992.15 \\
\hline \multirow{5}{*}{$\mathrm{A}$} & -20 & 0.443718 & 77.5431 & 31.8732 & 2051.34 \\
\cline { 2 - 6 } & -10 & 0.462178 & 77.6550 & 33.2614 & 2022.64 \\
\cline { 2 - 6 } & +10 & 0.497035 & 77.8663 & 35.8780 & 1968.43 \\
\cline { 2 - 6 } & +20 & 0.513573 & 77.9666 & 37.1171 & 1942.70 \\
\cline { 2 - 6 } & -20 & 0.511087 & 73.6465 & 41.7256 & 2615.13 \\
\cline { 2 - 6 } & -10 & 0.493806 & 75.7018 & 37.9337 & 2295.32 \\
\cline { 2 - 6 } & +10 & 0.469056 & 79.8307 & 31.6210 & 1713.90 \\
\cline { 2 - 6 } & +20 & 0.460971 & 81.9087 & 28.9470 & 1451.60 \\
\hline
\end{tabular}

From sensitivity Table 1 the following inferences are drawn:

1. From Table 1 it is clear that the total profit per unit time $\mathrm{AP}_{1}\left(\mathrm{~T}^{*}, \mathrm{p}^{*}\right)$ increases or decreases with increase or decrease in the values of model parameters $\mathrm{a}, \mathrm{b}$ and $\mathrm{I}_{\mathrm{e}}$, while $\mathrm{AP}_{1}\left(\mathrm{~T}^{*}, \mathrm{p}^{*}\right)$ decreases or increases with increase or decrease in the values of $c, \theta, I_{c}, h, C_{d}, A$ and $\mathrm{C}_{\mathrm{p}}$. The obtained results show that $\mathrm{AP}_{1}\left(\mathrm{~T}^{*}, \mathrm{p}^{*}\right)$ is highly sensitive to changes in a, c and $\mathrm{C}_{\mathrm{p}}$. It is moderately sensitive to changes in $b, I_{e}, \theta, I_{c}, h, C_{d}$ and $\mathrm{A}$.

2. From Table 1 it is clear that $Q^{*}$ increases or decreases with increase or decrease in the values of model parameters a, b and A, while $Q^{*}$ decreases or increases with increase or decrease in the values of model parameters $I_{e}, c, \theta, I_{c}, h, C_{d}$ and $C_{p}$. The obtained results show that $Q^{*}$ is highly sensitive to changes in a and $\mathrm{C}_{\mathrm{p}}$. It is fairly sensitive to changes in $\mathrm{b}, \mathrm{c}, \theta, \mathrm{I}_{\mathrm{e}}, \mathrm{I}_{\mathrm{c}}, \mathrm{h}$ and $\mathrm{C}_{\mathrm{d}}$.
Example (2): (For case (2) $\mathrm{T}_{1}<\mathrm{M} \leq \mathrm{T}$ ) $\mathrm{We}$ consider the following data in appropriate units: $\mathrm{a}=200, \mathrm{~b}=0.5, \mathrm{c}=1.8$, $\theta=0.3, I_{e}=0.15, I_{c}=0.17, \mathrm{M}=0.4, \mathrm{~h}=6, \delta=0.1, \mathrm{C}_{\mathrm{d}}=3, \mathrm{~A}=130$, $\mathrm{C}_{\mathrm{p}}=40, \mathrm{~T}_{1}=0.32$. Then, the optimal solution is $\mathrm{T}^{*}=0.437287$, $\mathrm{p}^{*}=76.8656, \mathrm{Q}^{*}=31.9856$ and $\mathrm{AP}_{2}\left(\mathrm{~T}^{*}, \mathrm{P}\right)=2137.46$. The concavity of the profit function for case (2) is shown graphically in Figure 3.

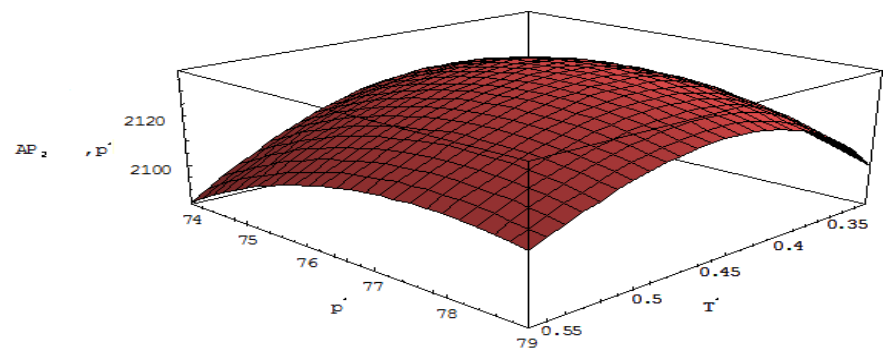

Figure 3. The concavity of the profit function (for case (2)) w.r.t. selling price and cycle length

Table 2: The sensitivity analysis for case (2) is performed by changing the value of each of the parameters by $\pm 10 \%$ and $\pm 20 \%$, taking one parameter at a time and keeping the remaining parameters unchanged.

\begin{tabular}{|l|l|l|l|l|l|}
\hline Parameter & \% Change & $\mathrm{T}^{*}$ & $\mathrm{p}^{*}$ & $\mathrm{Q}^{*}$ & $\mathrm{AP}_{2}\left(\mathrm{~T}^{*}, \mathrm{p}^{*}\right)$ \\
\hline \multirow{3}{*}{$\mathrm{A}$} & -20 & 0.505166 & 66.1738 & 24.9677 & 819.376 \\
\cline { 2 - 6 } & -10 & 0.46407 & 71.4760 & 28.4890 & 1412.65 \\
\cline { 2 - 6 } & +10 & 0.419408 & 82.3099 & 35.5644 & 2992.16 \\
\cline { 2 - 6 } & +20 & 0.407566 & 87.7915 & 39.2910 & 3975.75 \\
\hline \multirow{3}{*}{ B } & -20 & 0.4137 & 76.7314 & 29.5532 & 2084.12 \\
\cline { 2 - 6 } & -10 & 0.425441 & 76.7991 & 30.7480 & 2110.36 \\
\cline { 2 - 6 } & +10 & 0.449248 & 76.9309 & 33.4628 & 2165.35 \\
\cline { 2 - 6 } & +20 & 0.461332 & 76.9951 & 34.5976 & 2194.30 \\
\hline
\end{tabular}


International Journal of Computer Applications (0975 - 8887) Volume 113 - No. 11, March 2015

\begin{tabular}{|c|c|c|c|c|c|}
\hline \multirow[t]{4}{*}{$\mathrm{C}$} & -20 & 0.439337 & 90.7672 & 36.1470 & 3550.83 \\
\hline & -10 & 0.436382 & 83.0328 & 33.9014 & 2755.15 \\
\hline & +10 & 0.441502 & 71.8413 & 30.2942 & 1649.25 \\
\hline & +20 & 0.448791 & 67.6777 & 28.7547 & 1258.28 \\
\hline \multirow[t]{4}{*}{$\Theta$} & -20 & 0.463019 & 76.7210 & 33.7641 & 2176.99 \\
\hline & -10 & 0.449706 & 76.7946 & 32.8466 & 2157.00 \\
\hline & +10 & 0.425666 & 76.9341 & 31.1754 & 2118.34 \\
\hline & +20 & 0.414758 & 77.0003 & 30.4108 & 2099.63 \\
\hline \multirow[t]{4}{*}{$\mathrm{I}_{\mathrm{e}}$} & -20 & 0.457965 & 77.1366 & 33.4297 & 2100.62 \\
\hline & -10 & 0.447758 & 77.0029 & 32.7189 & 2118.84 \\
\hline & +10 & 0.426532 & 76.7242 & 31.2284 & 2156.50 \\
\hline & +20 & 0.415468 & 76.5783 & 30.4452 & 2176.00 \\
\hline \multirow[t]{4}{*}{$\mathrm{I}_{\mathrm{c}}$} & -20 & 0.439318 & 76.8772 & 32.1423 & 2137.60 \\
\hline & -10 & 0.438276 & 76.8712 & 32.0619 & 2137.53 \\
\hline & +10 & 0.436349 & 76.8602 & 31.9133 & 2137.40 \\
\hline & +20 & 0.435456 & 76.8551 & 31.8444 & 2137.33 \\
\hline \multirow[t]{4}{*}{$\mathrm{H}$} & -20 & 0.448864 & 76.8075 & 32.9980 & 2155.71 \\
\hline & -10 & 0.442965 & 76.8367 & 32.4842 & 2146.52 \\
\hline & +10 & 0.431817 & 76.8941 & 31.5086 & 2128.53 \\
\hline & +20 & 0.426542 & 76.9222 & 31.0494 & 2119.72 \\
\hline \multirow[t]{4}{*}{$\mathrm{C}_{\mathrm{d}}$} & -20 & 0.438968 & 76.8570 & 32.1324 & 2140.17 \\
\hline & -10 & 0.438125 & 76.8613 & 32.0588 & 2138.81 \\
\hline & +10 & 0.436454 & 76.8699 & 31.9129 & 2136.11 \\
\hline & +20 & 0.435625 & 76.8742 & 31.8406 & 2134.77 \\
\hline \multirow[t]{4}{*}{ A } & -20 & 0.397256 & 76.6158 & 28.9131 & 2199.77 \\
\hline & -10 & 0.417757 & 76.7440 & 30.4874 & 2167.87 \\
\hline & +10 & 0.455973 & 76.9814 & 33.4177 & 2108.35 \\
\hline & +20 & 0.473915 & 77.0923 & 34.7914 & 2080.39 \\
\hline \multirow[t]{4}{*}{$\mathrm{C}_{\mathrm{p}}$} & -20 & 0.463193 & 72.8865 & 38.0963 & 2759.07 \\
\hline & -10 & 0.448716 & 74.8732 & 36.7689 & 2430.82 \\
\hline & +10 & 0.428556 & 78.8655 & 29.4405 & 1853.74 \\
\hline & +20 & 0.422311 & 80.8751 & 27.1526 & 1587.74 \\
\hline
\end{tabular}


From sensitivity Table 2 the following inferences are drawn:

1. From Table 2 it can be shown that the total profit per unit time $\mathrm{AP}_{2}\left(\mathrm{~T}^{*}, \mathrm{p}^{*}\right)$ increases or decreases with increase or decrease in the values of model parameters $\mathrm{a}, \mathrm{b}$ and $\mathrm{I}_{\mathrm{e}}$, while $\mathrm{AP}_{2}\left(\mathrm{~T}^{*}, \mathrm{p}^{*}\right)$ decreases or increases with increase or decrease in the values of $\mathrm{c}, \theta, \mathrm{I}_{\mathrm{c}}, \mathrm{h}, \mathrm{C}_{\mathrm{d}}, \mathrm{A}$ and $\mathrm{C}_{\mathrm{p}}$. The obtained results show that $\mathrm{AP}_{2}\left(\mathrm{~T}^{*}, \mathrm{p}^{*}\right)$ is highly sensitive to changes in $\mathrm{a}, \mathrm{c}$ and $\mathrm{C}_{\mathrm{p}}$. It is moderately sensitive to changes in $\mathrm{b}, \mathrm{I}_{\mathrm{e}}, \theta, \mathrm{I}_{\mathrm{c}}, \mathrm{h}, \mathrm{C}_{\mathrm{d}}$ and $\mathrm{A}$.

2. From Table 2 it is clear that $Q^{*}$ increases or decreases with increase or decrease in the values of model parameter a, b and $\mathrm{A}$, while $Q^{*}$ decreases or increases with increase or decrease in the values of model parameters $\mathrm{I}_{e}, \mathrm{c}, \theta, \mathrm{I}_{\mathrm{c}}, \mathrm{h}, \mathrm{C}_{\mathrm{d}}$ and $\mathrm{C}_{\mathrm{p}}$. The obtained outcomes show that $Q^{*}$ is highly sensitive to changes in a and $\mathrm{C}_{\mathrm{p}}$. It is fairly sensitive to changes in $\mathrm{b}, \mathrm{c}, \theta, \mathrm{I}_{\mathrm{e}}, \mathrm{I}_{\mathrm{c}}, \mathrm{h}$ and $\mathrm{C}_{\mathrm{d}}$.
Example (3): (For case case (3) $\mathrm{M}>\mathrm{T}$ ) We consider the following data in appropriate units: $a=200, b=0.5, c=1.8$, $\theta=0.3, \mathrm{I}_{\mathrm{e}}=0.15, \mathrm{I}_{\mathrm{c}}=0.17, \mathrm{M}=0.6, \mathrm{~h}=6, \delta=0.1, \mathrm{C}_{\mathrm{d}}=3, \mathrm{~A}=130$, $\mathrm{C}_{\mathrm{p}}=40, \mathrm{~T}_{1}=0.32$. Then the optimal solution is $\mathrm{T}^{*}=0.533367$, $\mathrm{P}^{*}=76.6228, \mathrm{Q}^{*}=40.3092$ and $\mathrm{AP}_{3}\left(\mathrm{~T}^{*}, \mathrm{p}^{*}\right)=2335.76$. The concavity of the profit function for case (3) is shown graphically in Figure 4.

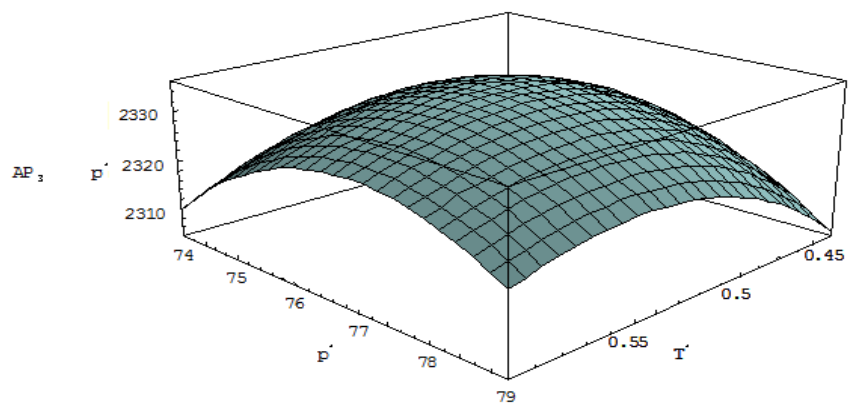

Figure 4. The concavity of the profit function (for case (3)) w.r.t. selling price and cycle length

Table 3: The sensitivity analysis for case (3) is performed by changing the value of each of the parameters by $\pm 10 \%$ and $\pm 20 \%$, taking one parameter at a time and keeping the remaining parameters unchanged.

\begin{tabular}{|c|c|c|c|c|c|}
\hline Parameter & $\%$ Change & $\mathrm{T}^{*}$ & $\mathrm{p}^{*}$ & $Q^{*}$ & $\mathrm{AP}_{3}\left(\mathrm{~T}^{*}, \mathrm{p}^{*}\right)$ \\
\hline \multirow[t]{4}{*}{ A } & -20 & 0.572862 & 65.699 & 29.3877 & 943.221 \\
\hline & -10 & 0.547164 & 71.1321 & 34.7295 & 1571.94 \\
\hline & +10 & 0.526602 & 82.1469 & 46.1678 & 3233.83 \\
\hline & +20 & 0.524254 & 87.6915 & 52.3155 & 4265.78 \\
\hline \multirow[t]{4}{*}{ B } & -20 & 0.515395 & 76.5623 & 37.9615 & 2271.33 \\
\hline & -10 & 0.524301 & 76.5925 & 39.1135 & 2303.17 \\
\hline & +10 & 0.542601 & 76.6531 & 41.5507 & 2369.13 \\
\hline & +20 & 0.552008 & 76.6834 & 42.8402 & 2403.27 \\
\hline \multirow[t]{4}{*}{$\mathrm{C}$} & -20 & 0.545945 & 90.5707 & 46.3861 & 3816.94 \\
\hline & -10 & 0.537996 & 82.8173 & 43.1686 & 2983.27 \\
\hline & +10 & 0.531747 & 71.5647 & 37.7266 & 1823.53 \\
\hline & +20 & 0.532992 & 67.3618 & 35.3589 & 1412.70 \\
\hline \multirow[t]{4}{*}{$\Theta$} & -20 & 0.559388 & 76.3880 & 42.0822 & 2384.37 \\
\hline & -10 & 0.546004 & 76.5070 & 41.1737 & 2359.86 \\
\hline & +10 & 0.521414 & 76.7358 & 39.4850 & 2312.07 \\
\hline & +20 & 0.510088 & 76.8461 & 38.6983 & 2288.76 \\
\hline \multirow[t]{2}{*}{$\mathrm{I}_{\mathrm{e}}$} & -20 & 0.538529 & 76.9201 & 40.3995 & 2262.61 \\
\hline & -10 & 0.535847 & 76.7701 & 40.3482 & 2299.13 \\
\hline
\end{tabular}




\begin{tabular}{|c|c|c|c|c|c|}
\hline & +10 & 0.531069 & 76.4781 & 40.2811 & 2372.49 \\
\hline & +20 & 0.528932 & 76.3358 & 40.2625 & 2409.32 \\
\hline \multirow[t]{4}{*}{$\mathrm{H}$} & -20 & 0.545048 & 76.5255 & 41.4261 & 2358.32 \\
\hline & -10 & 0.539109 & 76.5745 & 40.8576 & 2346.97 \\
\hline & +10 & 0.527814 & 76.6706 & 39.7796 & 2324.70 \\
\hline & +20 & 0.522438 & 76.7179 & 39.2678 & 2313.76 \\
\hline \multirow[t]{4}{*}{$\mathrm{C}_{\mathrm{d}}$} & -20 & 0.535070 & 76.6084 & 40.4717 & 2339.11 \\
\hline & -10 & 0.534216 & 76.6156 & 40.3902 & 2337.44 \\
\hline & +10 & 0.532523 & 76.6300 & 40.2286 & 2334.10 \\
\hline & +20 & 0.531682 & 76.6372 & 40.1484 & 2332.43 \\
\hline \multirow[t]{4}{*}{ A } & -20 & 0.507122 & 76.5016 & 38.2080 & 2385.74 \\
\hline & -10 & 0.520409 & 76.5626 & 39.2719 & 2360.44 \\
\hline & +10 & 0.546022 & 76.6822 & 41.3218 & 2311.68 \\
\hline & +20 & 0.558394 & 76.7408 & 42.3115 & 2288.14 \\
\hline \multirow[t]{4}{*}{$\mathrm{C}_{\mathrm{p}}$} & -20 & 0.555727 & 72.6724 & 47.0640 & 2976.68 \\
\hline & -10 & 0.54362 & 74.6468 & 43.5469 & 2647.11 \\
\hline & +10 & 0.52486 & 78.6015 & 37.3118 & 2042.45 \\
\hline & +20 & 0.51804 & 80.5841 & 34.5221 & 1767.00 \\
\hline
\end{tabular}

From sensitivity Table 3 the following inferences are drawn:

1. From Table 3 it is clear that the total profit per unit time $\mathrm{AP}_{3}\left(\mathrm{~T}^{*}, \mathrm{p}^{*}\right)$ increases or decreases with increase or decrease in the values of model parameters $\mathrm{a}, \mathrm{b}$ and $\mathrm{I}_{\mathrm{e}}$, even as $\mathrm{AP}_{3}\left(\mathrm{~T}^{*}, \mathrm{p}^{*}\right)$ decreases or increases with increase or decrease in the values of $c, \theta, h, C_{d}$, $A$ and $C_{p}$. The attained results show that $\mathrm{AP}_{3}\left(T^{*}, p^{*}\right)$ is highly sensitive to changes in a, c and $\mathrm{C}_{\mathrm{p}}$. It is moderately sensitive to changes in $b, I_{e}, \theta, h, C_{d}$ and A.

2. From Table 3 it is clear that $Q^{*}$ increases or decreases with increase or decrease in the values of model parameters a, b and A, whereas $Q^{*}$ decreases or increases with increase or decrease in the values of model parameters $\mathrm{I}_{\mathrm{e}}, \mathrm{c}, \theta, \mathrm{h}, \mathrm{C}_{\mathrm{d}}$ and $\mathrm{C}_{\mathrm{p}}$. The obtained results show that $Q^{*}$ is highly sensitive to changes in a and $\mathrm{C}_{\mathrm{p}}$. It is fairly sensitive to changes in $b, c, \theta, I_{e}$, h and $C_{d}$.

\section{CONCLUSION}

In this study, an inventory model is developed with the facility of allowable delay in payment. The consumption rate is considered as a function of on hand inventory and selling price of the products. During the development of the model it is assumed that the on hand inventory affects the demand rate only up to a certain time and after that only selling price affects the demand rate. According this theme three cases arise; all the cases are discussed and illustrated with the help of some numerical examples. Sensitivity analyses of system parameters clarify that $\mathrm{a}, \mathrm{c}$ and $\mathrm{C}_{\mathrm{p}}$ should be considered carefully.

There are several hopeful areas for further research. This model can be extended by considering probabilistic or inflation induced market demand rate. Another area for further research is that quantity discounted cash flow can be assumed.

\section{REFERENCES}

[1] Levin, R.I., McLaughlin, C.P., Lamone, R.P., and Kottas, J.F., (1972). Production/Operations Management: Contemporary Policy for Managing Operating Systems. McGraw-Hill, New York.

[2] Silver, E.A., and Peterson, R., (1985). Decision Systems for Inventory Management and Production Planning. Second ed. John Wiley, New York.

[3] Goyal, S.K., (1985). Economic order quantity under conditions of permissible delay in payments. Journal of the Operational Research Society, 36(4), 335-338.

[4] Gupta, R., and Vrat, P., (1986). Inventory model for stock-dependent consumption rate. Opsearch, 23, 19-24. 
[5] Mandal, B.N., and Phaujdar, S., (1989). An inventory model for deteriorating with stock dependent consumption rate. Opsearch, 26, 43-46.

[6] Datta, T.K., and Pal, A.K., (1990). Deterministic inventory systems for deteriorating items with inventorylevel-dependent demand rate and shortages. Opsearch, $27,167-176$.

[7] Padmanabhan, G., and Vrat, P., (1995). EOQ models for perishable items under stock dependent selling rate. European Journal of Operational Research, 86, 281-292.

[8] Aggarwal, S.P., and Jaggi, C.K., (1995). Ordering policies of deteriorating items under permissible delay in payments. Journal of the Operational Research Society, 46(5), 658-662.

[9] Jamal, A.M.M., Sarker, B.R., and Wang, S., (1997). An ordering policy for deteriorating items with allowable shortages and permissible delay in payment. Journal of the Operational Research Society, 48, 826-833

[10] Urban, T.L., and Baker, R.C., (1997). Optimal ordering and pricing policies in a single-period environment with multivariate demand and markdowns. European Journal of Operational Research, 103, 573-583.

[11] Datta, T.K., and Paul, K., (2001). An inventory system with stock-dependent, price-sensitive demand rate. Production Planning \& Control, 12, 13-20.

[12] Chang, H.J., and Dye, C.Y., (2001). An inventory model for deteriorating items with partial backlogging and permissible delay in payments. International Journal of Systems Science, 32, 345-352.
[13] Teng, J.T., (2002). On the economic order quantity under conditions of permissible delay in payments. Journal of the Operational Research Society, 53, 915-918.

[14] You, P.S., (2005). Inventory policy for products with price and time dependent demand. Journal of the Operational Research Society, 56, 870-873.

[15] You, P.S., and Hsieh, Y.C., (2007). An EOQ model with stock and price sensitive demand. Mathematical and Computer Modelling, 45, 933-942.

[16] Sana, S.S., and Chaudhuri, K.S., (2008). A deterministic EOQ model with delays in payments and price-discount offers. European Journal of Operational Research, 184, 509-533.

[17] Chang, C.T., Chen, Y.J., Tsai, T.R. and Wu S.J., (2010). Inventory models with stock- and price dependent demand for deteriorating items based on limited shelf space. Yugoslav Journal of Operations Research, 20, 5569.

[18] Khanra, S., Ghosh, S.K. and Chaudhuri, K.S., (2011). An EOQ model for a deteriorating item with time dependent quadratic demand under permissible delay in payment. Applied Mathematics and Computation, 218, 1, 1-9.

[19] Teng, J. T., Min, J., and Pan, Q., (2012). Economic order quantity model with trade credit financing for nondecreasing demand. Omega, 40(3), 328-335.

[20]Lee, Y. P., and Dye, C. Y., (2012). An inventory model for deteriorating it ems under stock-dependent demand and controllable deterioration rate. Computers \& Industrial Engineering, 63(2) 474-482. 